\title{
USE OF LARYNGEAL MASK AIRWAY IN PAEDIATRIC EXTERNAL DACROCYSTORHINOSTOMY SURGERY UNDER ANAESTHESIA: A RETROSPECTIVE STUDY
}

\author{
Laxmi Pathak ${ }^{1}$
}

\section{ABSTRACT}

INTRODUCTION: Many recent studies have shown the use of Laryngeal Mask Airway (LMA) in Adenotonsillectomy but not in Dacryocystorhinostomy (DCR) surgery in paediatric age group. So, this study was carried out to evaluate the safety of LMA use in Pediatric External Dacryocystorhinostomy performed under General Anaesthesia.

MATERIAL AND METHOD:This retrospective study was carried out by collecting the data of 96 children with American Society of Anesthesiologists (ASA) physical status 1 from Lumbini Eye Institute (Memorandum of Understanding with UCMS), Bhairahawa, Nepal from September 2008 to June 2014 to find out any significant cardiorespiratory complications associated with the use of LMA.

RESULTS: This study found no significant cardio-respiratory complications during insertion and after removal of LMA. Though airway obstruction and laryngospasm had occurred in few children, it was easily managed by bag and mask ventilation. Time taken to shift the patients from Operation Theatre to Post Anaesthesia Care Unit (PACU) was also less, average 13 minutes.

CONCLUSION: This study showed that LMA can safely be used in children undergoing External Dacryocystorhinostomy under general anesthesia with the use of intermittent suctioning and without any interruption in surgery.

KEY WORDS Dacryocystorhinostomy; General Anaesthesia; LMA; Pediatric

1. Associate Professor, Department of Anaesthesiology, Universal College of Medical Sciences \& Teaching Hospital, Bhairahawa, Nepal

\author{
For Correspondence \\ Dr. Laxmi Pathak \\ Associate Professor \\ Department of Anaesthesiology, \\ Universal College of Medical Sciences \& Teaching \\ Hospital, Bhairahawa, Nepal \\ Email:laxmi_pathak22@yahoo.com
}




\section{INTRODUCTION}

Management of the airway in paediatric patients required an understanding and knowledge of unique characteristics of their airway as compared to adult's airway. At present, LMA is considered a standard device for paediatric airway management. ${ }^{1,2}$ It is also helpful in the management of difficult or failed intubation. ${ }^{3-5}$ It does not alter haemodynamics during insertion and is associated with very few side effects than endotracheal intubation. In recent years, LMA has been used with increasing frequency as an alternative to endotracheal intubation in paediatric population. ${ }^{6}$

External Dacryocystorhinostomy is a more extensive procedure involving surgical exposure of the duct and creating a new opening from it into the nasal cavity through the bony upper lateral aspect of the nose. As blood may pass into the nasopharynx, airway protection with a tracheal tube and throat pack is necessary. But, it has been suggested that LMA protects both paediatric and adult airways against blood, secretions and debris during dental and otorhinolaryngological surgeries, which has been confirmed by fiberoptic endoscopy. ${ }^{7,8}$ As literature search did not reveal much regarding the use of laryngeal mask airways in paediatric DCR till date, this study was carried out on retrospective data to find out the safety of its use in paediatric DCR under general anaesthesia.

\section{MATERIAL AND METHOD}

Information and Data was collected from the records of $96(50$ girls and 46 boys) paediatric patients undergone External Dacrocystorhinostomy under General Anaesthesia by using Classical LMA from September 2008 to June 2014 in Lumbini Eye Institute, mainly to find out any complications in relation to LMA insertion or removal or any other cardio-respiratory complications that had occurred if any. All children were of ASA 1 physical status without any significant illness, aged between 3 to 14 years and with adequate Nil Per Oral status. Records showed that surgery under anesthesia was carried out only after taking informed written consent from their guardians. None of the patients received premedication. Out of 96 patients, intravenous access of 16 patients was done after inhalational induction with Halothane. In rest of the children, it was done in the patient's holding area without any medication and induction of anesthesia in these children was done with intravenous Propofol. The Preoperative, Intraoperative and Postoperative vitals (heart rate, blood pressure, oxygen saturation and respiratory rate) were recorded. Intravenous Propofol $2-3 \mathrm{mg} / \mathrm{kg}$ and intravenous Butorphanol 0.25-0.5 mg was used for induction of anesthesia and analgesia respectively. Adequate depth of anaesthesia was achieved by providing Halothane \& Oxygen via bag \& mask ventilation. The size of the LMA used was according to the manufacturer's specifications. The technique of LMA insertion was Reverse Classical technique with fully deflated cuff and $1 \equiv$ cation. Maintenance of anaesthesia was done with Oxygen and $2 \%$ Halothane on spontaneous respiration. Dextrose Normal Saline was infused intraoperatively. Suction catheter was inserted to the oral cavity towards the side of incision. 1-2 $\mathrm{ml}$ of 2\% Lignocaine with adrenaline 1:200000 was infiltrated before skin incision. After the surgery was completed, LMA was removed and patients were shifted to PACU with oxygen supplementation via face mask.

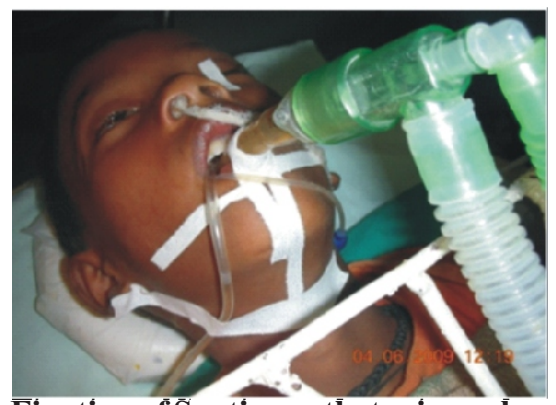

Picture 1: Fixation of Suction catheter in oral cavity

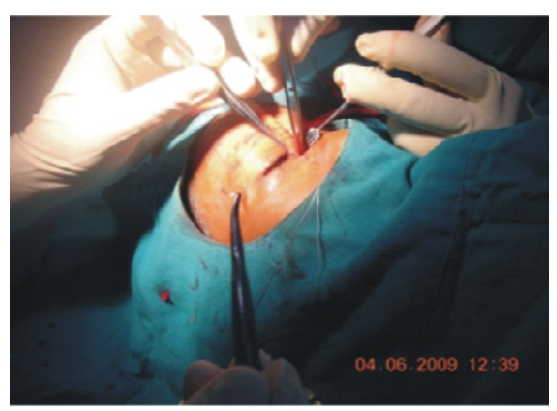

Picture 2: Surgical site intra-operatively

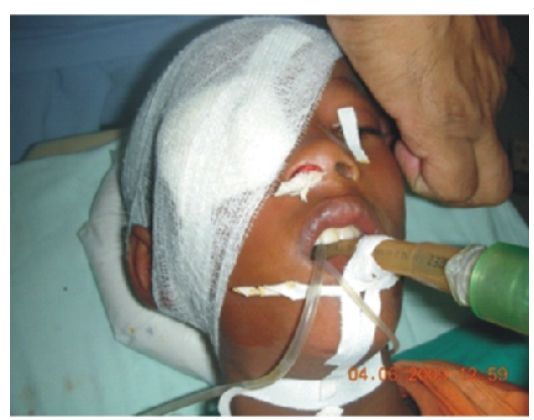

Picture 3: Bandaging before LMA removal 


\section{RESULTS}

LMA insertion was repeated in two patients. There were no records of any malpositioning, displacement, kinking or biting of the LMA throughout the procedure. Intraoperative suctioning was done in all the patients without any interruption of surgery. Two patients received intravenous Atropine $0.1-0.2 \mathrm{mg}$ intra-operatively for Bradycardia. Postoperative Sedation scores at the time of shifting the patients from Operation room were not recorded. Bronchospasm, aspiration, stridor, coughing and trauma did not occur in any of the patients but five patients experienced airway obstruction and one patient experienced laryngospasm after removal of LMA and were treated with Guedel's oropharyngeal airways, jaw thrust, $100 \%$ oxygen and positive pressure ventilation. Injection Succinylcholine was not required for the treatment of laryngospasm. Removal of LMA was done with inflated cuff in all patients.

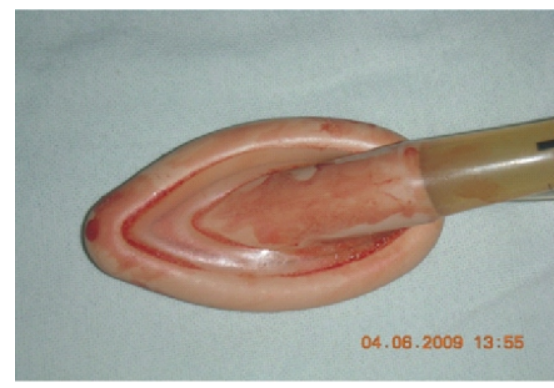

\section{Picture4: LMA with inflated cuff after removal}

Average duration of anesthesia (from induction to operation room exit time) was 76 minutes whereas average duration of surgery (from skin incision to closure) was 63 minutes. It took 13 minutes in average to shift these children out of the operation room. The average duration of stay in PACU was also only 14 minutes.

Table 1.Preoperative and postoperative vitals

\begin{tabular}{|l|l|l|l|}
\hline Parameters & \multicolumn{1}{|c|}{$\begin{array}{c}\text { Preoperative } \\
\text { (Mean } \pm \text { Standard Deviation) }\end{array}$} & $\begin{array}{c}\text { Postoperative } \\
\text { (Mean } \pm \text { Standard Deviation) }\end{array}$ & P-Value \\
\hline $\begin{array}{l}\text { Heart Rate } \\
\text { (beats/minute) }\end{array}$ & $92 \pm 7.8$ & $86 \pm 9.6$ & 4.7 \\
\hline $\begin{array}{l}\text { Systolic BP } \\
(\mathrm{mmHg})\end{array}$ & $95 \pm 9.1$ & $93 \pm 5.8$ & 1.8 \\
\hline $\begin{array}{l}\text { Diastolic BP } \\
(\mathrm{mmHg})\end{array}$ & $52 \pm 6.6$ & $52 \pm 5$ & 0 \\
\hline $\mathrm{SPO}_{2}(\%)$ & $100 \pm 0$ & $100 \pm 0$ & 0 \\
\hline $\begin{array}{l}\mathrm{RR} \\
\text { (breaths/minute) }\end{array}$ & $13 \pm 1.2$ & $13.677 \pm 1.30$ & -1.3 \\
\hline
\end{tabular}

Table 2. Anaesthesia, surgery and recovery room stay time

\begin{tabular}{|l|c|}
\hline Parameters (minutes) & (Mean \pm Standard Deviation) \\
\hline Duration of Anaesthesia & $76.1 \pm 3.35$ \\
\hline Duration of Surgery & $63.4 \pm 3.5$ \\
\hline Recovery Room stay time & $14.5 \pm 2.5$ \\
\hline
\end{tabular}

\section{DISCUSSION}

Unlike adults, children requiring eye or nasolacrimal duct surgery do not tolerate sedation and local anaesthetic techniques and therefore almost always require general anaesthesia. In pediatric anesthesia, respiratory complications such as bronchospasm, laryngospasm and hypoxemia are common especially during adenotonsillectomies because of patient's small airways, hyper-reactivity to infectious and inflammatory processes and the presence of secretions and blood. Laryngospasm is among the most feared respiratory complications, occurring in 0.1 to $27 \%$ of cases, causing severe hypoxemia and requiring immediate treatment. The factors that increase the risk of laryngospasm include small children, endotracheal intubation, inhalation anesthesia, inadequate anesthesia depth, respiratory infections and the presence of secretions in the pharynx. ${ }^{9}$ The incidence of laryngospasm in children associated with endotracheal intubation ranges from $4 \%$ to $14 \% .{ }^{10}$

Though endotracheal intubation is the standard means to secure the airway in children undergoing Adenotonsillectomy, it has many disadvantages. Laryngoscopy and intubation is associated with significant increase in sympathoadrenal activity manifested by tachycardia, hypertension, raised intraocular pressure, elevation of plasma catecholamines, breath holding, coughing, laryngospasm and bronchospasm. ${ }^{6,11-13}$ In an attempt to reduce the risks associated with endotracheal intubation, Williams et $\mathrm{a}^{14}$ used a reinforced laryngeal mask airway during anesthesia for otorhinolaryngology and reported a reduced incidence of laryngospasm, cough and hypoxemia. Similarly, removal of LMA seems to be associated with fewer sequelae than extubation of tracheal tube. ${ }^{11}$ It causes less coughing, straining and breath holding during emergence from anaesthesia. ${ }^{12}$ Respiratory complications associated with removal of LMA have been found unrelated to the depth of anaesthesia. ${ }^{15}$ In addition, the incidence of bronchospasm was found to be less with LMA when compared to endotracheal tube (ETT) and other respiratory complications were also decreased by $50 \% .{ }^{16}$ LMA is relatively simple to use. Its insertion does not require laryngoscope and neuromuscular blocking agents. It is inserted blindly into the pharynx forming a low-pressure seal around the laryngeal inlet and permitting spontaneous as well 
as gentle positive-pressure ventilation. Insertion techniques commonly used are the standard or classical technique, $180^{\circ}$ rotation technique or reverse technique, fully or partially inflated cuff technique and techniques based on head position. The main problem during its placement is to pass the posterior wall. The standard insertion technique recommended by Brain using a fully deflated cuff has demonstrated a varying degree of successful insertion on the first attempt in children between 67 to $90 \%$. The incidence of sore throat is $30 \%$ with the classic insertion method. This rate is $23.3 \%$ when using the inflated cuff method with less mucosal trauma. ${ }^{16,17}$ Kundra et $a l^{18}$ proposed lateral approach of LMA insertion and found to be associated with a higher degree of uvula and posterior pharyngeal wall injury. In the reverse classic method, LMA is inserted upside down into the mouth and when resistance is sensed, it is twisted to $180^{\circ}$. Then the cuff is inflated based on the size of LMA. Soh and $\mathrm{Ng}^{19}$, in 2001 also demonstrated that the reverse technique is a more efficient technique in $100 \%$ of paediatric patients as compared to $90 \%$ of efficacy with the standard technique. Jaw thrust maneuver and laryngoscopeguided placement have also been advocated to ease placement of the classic LMA. We did not find any records of postoperative sore throat in these children. The technique used to insert LMA in this study was also highly efficient requiring repeat insertion in only 2 children.

Correct positioning of LMA is more difficult in children because of higher larynx as compared to adults. Higher incidence of malposition was found especially with the use of smaller sizes. This is because of the fact that pediatric LMAs are similar in structure but smaller in size to those of adults and are not custom-made for children according to the anatomy of pediatric airways. LMA size was chosen according to the manufacturer recommendation and the cuff was inflated with the recommended maximum volume of air in all patients. No single case of malpositioning was recorded in this study. Apart from malpositioning, use of LMA may also be associated with other complications like several attempts for its accurate placement, failure to ventilate effectively and risk of aspiration of stomach contents etc. The incidence of these complications depends on the performer's expertise and can also result from inadequate depth of anesthesia, wrong size and high peak inspiratory pressure over $15 \mathrm{~cm} \mathrm{H} 2 \mathrm{O}$ causing stomach inflation. ${ }^{16}$ The incidence of regurgitation when the LMA is correctly positioned is very less, only $0.1 \%$ and is due to superficial depth of anaesthesia and high inspiratory pressure. ${ }^{9,20}$ But, in this study, there were no any case of aspiration or any serious respiratory complications even after the removal of LMA. The study done in patients undergoing adenotonsillectomy found that after removal of LMA, the part of the mask that maintained contact with the larynx was bloody in some cases. There were no such observations recorded in this study. However, intermittent suctioning was done during surgery in all cases.

Angela et al. ${ }^{6}$ has found LMA more efficient than ETT in adenotonsillectomy. Time between the end of surgery and extubation was significantly shorter in the LMA group by 4.06 minutes. The total anesthesia time (the time from placement of the face mask for inhalation induction to operating room exit) was shorter in the LMA group by 6.08 minutes. Improving efficiency in the operating room has been a major focus of hospital administrators during the past decade. ${ }^{21}$ The records in this study also showed less time to shift the patient from Operation Theatre after surgery completed so that next case could be done earlier without losing time.

Problems of tube kinking, malpositioning or displacement like in adenotonsillectomy was not found in the records and this might be because of different surgical site as compared to adenotonsillectomy. By using LMA in paediatric Dacrocystorhinostomy surgery, complications related to endotracheal intubation and extubation, use of throat pack and muscle relaxants can also be avoided.

\section{CONCLUSION}

This retrospective study concluded that Classical LMA can be used safely as an airway device to deliver general anaesthesia in paediatric patient scheduled for External Dacrocystorhinostomy without any significant haemo-dynamic changes or respiratory complications throughout the procedure. More studies are required including the techniques of LMA insertion and removal, depth of anesthesia at which it should be inserted or removed, amount of air used to inflate the cuff of LMA, postoperative sedation scores, time to full awakening of the sedated children after shifting from operation room to PACU. Apart from vitals monitoring, continuous observation of the surgical procedure and recognizing the steps of need of suctioning by anaesthesiologist can help such patients to be free of many complications.

\section{ACKNOWLEGDEMENT}

I thank Dr. Salma K.C. Rai, Ophthalmologist \& Director, Lumbini Eye Institute for permitting me to conduct this study. 


\section{IREFERENCES}

1. Lopez-Gil M, Brimacombe J, Alvarez M. Safety and efficacy of the laryngeal mask airway: A prospective survey of 1400 children. Anaesthesia 1996; 51(10): 969-72.

http://dx.doi.org/10.1111/j.1365-2044.1996.tb14968.x PMid:8984875

2. Ho AM, Karmakar MK, Dion PW. Choosing the correct laryngeal mask airway sizes and cuff inflation volumes in pediatric patients. J Emerg Med 2008; 35 (3): 299- 300. http://dx.doi.org/10.1016/j.jemermed.2007.10.073 PMid:18462912

3. Walker RW, Ellwood J. The management of difficult intubation in children. Paediatr Anaesth 2009; 19 Suppl 1: 77- 87. http://dx.doi.org/10.1111/j.1460-9592.2009.03014.x; PMid:19572847

4. Brain AI. The laryngeal mask--a new concept in airway management. BrJ Anaesth 1983; 55 (8): 801- 5. http://dx.doi.org/10.1093/bja/55.8.801; PMid:6349667

5. Kinouchi K. Management of difficult pediatric airway. Masui 2006; 55 (1): 24-32. PMid:16440704

6. Angela Peng, MD; Kelley M. Dodson, MD; Leroy R. Thacker, PhD; Jeannette Kierce, MD; Jay Shapiro, MD; Cristina M. Baldassari, MD Use of Laryngeal Mask Airway in Pediatric Adenotonsillectomy. Arch Otolaryngol Head Neck Surg. 2011;137(1):42-46

http://dx.doi.org/10.1001/archoto.2010.230; PMid:21242545

7. Aziz L, Bashir K Comparison of armoured laryngeal mask airway with endotracheal tube for adenotonsillectomy. J Coll Physicians Surg Pak, 2006;16:685-688. PMid:17052415

8. Yazbeck-Karam VG, Aouad MT, Baraka AS Laryngeal mask airway for ventilation during diagnostic and interventional fibreoptic bronchoscopy in children. Paediatr Anaesth, 2003;13:691-694.

http://dx.doi.org/10.1046/j.1460-9592.2003.01145.x

9. Dante Ranieri Junior, TSA 1, Adecir Geraldo Neubauer, TSA 2, Denise Marchi Ranieri 3, Paulo do Nascimento Junior, TSA 4 The Use of Disposable Laryngeal Mask Airway for Adenotonsillectomies. Rev Bras Anestesiol 2012; 62: 6: 788798

10. Flick RP, Wilder RT, Pieper $S F$, et al. Risk factors for laryngospasm in children during general anesthesia. Paediatr Anaesth. 2008;18(4):289-296. http://dx.doi.org/10.1111/j.14609592.2008.02447.x

PMid:18315633

11. Jamal Abdelaziz, MD, Mohamad Alhashky, MD. Laryngeal Mask Airway in Ophthalmic Surgery; A Comparison Study. Bahrain Medical Bulletin, vol.22, No.4, December 2000
12. Motiang MJ, MBChB, MMed Rantloane JLA, MBChB, MMed. Intraocular pressure changes in patients undergoing cataract extraction and lens implantation: laryngeal mask airway versus endotracheal tube. SAJAA 2009; 15(2): 23-27

http://dx.doi.org/10.1080/22201173.2009.10872602

13. Qazi Ehsan Ali, Syed Hussain Amir, Uzma Firdaus, Abdulla Z Azhar. Comparison of the Flexi laryngeal mask airway vs. endotracheal intubation for paediatric ophthalmic surgery. IOSR Journal of Dental and Medical Sciences (IOSR-JDMS) eISSN: 2279-0853, p-ISSN: 2279-0861. Volume 4, Issue 4 (Jan.Feb. 2013), PP01-06

14. Williams PJ, Bailey PM Comparison of the reinforced laryngeal mask airway and tracheal intubation for adenotonsillectomy. $\mathrm{Br}$ JAnaesth, 1993;70:30-33.

http://dx.doi.org/10.1093/bja/70.1.30

15. Splinter WM, Reid $C W$ Removal of the laryngeal mask airway in children: deep anesthesia versus awake. J Clin Anesth, 1997;9:4-7. http://dx.doi.org/10.1016/S0952-8180(96)00217-6

16. Fatemeh Roodneshin, Mahvash Agah Novel Technique for Placement of Laryngeal Mask Airway in Difficult Pediatric Airways. Tanaffos (2011) 10(2), 56-68 PMid:25191364 PMCid:PMC4153147

17. Abhiruchi Patki. Laryngeal mask airway vs the endotracheal tube in paediatric airway management: A meta-analysis of prospective randomised controlled trials. Indian J Anaesth. 2011 Sep-Oct; 55(5): 537541.

http://dx.doi.org/10.4103/0019-5049.89900; PMid:22174478 PMCid:PMC3237161

18. Kundra P, Deepak R, Ravishankar M. Laryngeal Mask insertion in children: A rational approach. Paediatr Anaesth. 2003;13:68590. http://dx.doi.org/10.1046/j.1460 9592.2003.01134.x;PMid:14535906

19. Soh CR, $N g A S$. Laryngeal mask airway insertion in paediatric anaesthesia: Comparison between the reverse and standard technique. Anaesth Intensive Care. 2001;29:5159. PMid:11669434

20. Ismail-Zade IA, Vanner $R G$ Regurgitation and aspiration of gastric contents in a child during general anaesthesia using the laryngeal mask airway. Paediatr Anaesth, 1996;6:325-328. http://dx.doi.org/10.1111/j.1460-9592.1996.tb00458.x

21. Grisel J, Arjmand E. Comparing quality at an ambulatory surgery center and a hospital-based facility: preliminary findings. Otolaryngol Head Neck Surg. 2009; 141(6):701-709. 